\title{
A numerical solution for a closed die forging process
}

\author{
Dorin Luca* \\ "Gheorghe Asachi" Technical University of Iaşi, Department of Technologies and Equipments for \\ Materials Processing, 51, Prof.dr.doc. Dimitrie Mangeron Street, 700050 Iaşi, Romania
}

\begin{abstract}
One of the manufacturing processes that can be permanent improved is plastic deformation of metallic materials, as incorporating reserves on the manufacture of products with reduced material and energy consumptions. This paper presents finite element analysis for a closed die forging process, showing the stresses, strains and temperature into deformed part and stresses in the working tools. The analysis of obtained results for different flash dimensions of the working tools has enabled optimization of the forging process studied. To be able to validate the numerical results obtained, experimental tests were conducted. The compared data series show a good agreement between the numerical and experimental data.
\end{abstract}

\section{Introduction}

Closed die forging procedure continues to show particular interest because it can produce parts of various shapes and sizes, with high complexity, from different metals and alloys with moderate costs. For these reasons, research of the forging process in the closed die is current, aiming embodiments, investigation aspects of the interdependence of the various working parameters, the optimum temperature for forging and optimization of the die cavity for a good flow of the metal, increasing the life of the dies.

Companies that manufacture parts in closed die forging are interested in improving the quality and manufacture of net-shape parts [1]. A particular importance for achieving these goals has the designing process of the forging dies. Modern designing is a complex process which requires, among other things, the application of numerical methods for modelling and simulation based on the use of performant software. Finite element modelling offers solutions for metal forming processes, to identify fields of variation of displacements and stresses, mainly, and viewing the flow behaviour of the material.

The main elements that need to be considered when designing the dies are: flash dimensions, internal and external draft angles, fillet and corner radii, shrinkage and parting line of dies [2]. Closed forging dies can be made with one or more cavities depending on the shape and dimensions of the parts to be forged. Cavities fulfil the different roles in the forging process, and therefore can be classified into several types: forging finishing; preforging; cutting. Workpiece shapes obtained in each cavity and processes necessary to

${ }^{*}$ Corresponding author: $\underline{\text { dluca@ } @ \text { tuiasi.ro }}$ 
obtain these shapes represent forging steps.

Radev and Tomov [3] describe in their paper the role of shape complexity factor of part in the steps established of forging in closed die: multiple pre-forging or only a single forging. Closed die forging for parts with simple shape, generally symmetrical, can be made using billet with constant section. In the case of forgings with complex shape and asymmetrical, the use of workpieces with variable section is recommended to obtain the correct part with all details intact (e.g., ribs). Wei et al. [4] were concerned with unequal thickness billet design for isothermal forging of rib-web components from titanium alloys. This research aims to provide guidelines for designing the billet with unequal thickness, used to manufacture a wide range of precision components (without any under-filling defects) of titanium alloys.

Friction and wear forging dies are elements that must be considered for increasing the life of dies and avoidance of their failure. Chavoshi [5] performed a study on the influence of friction on the closed die forging of aluminium alloy AA7075. The process was simulated by finite volume method to compare the effect of two laws of friction (Coulomb's Amonton and Prandtl's) on the forging load, stresses and strains. Abachi et al. [6] have analyzed the hot forging die wear. By comparing the simulation results by the finite volume method with measurements made on the worn die, it was determined a value of the wear coefficient. Die wear is the main cause which leads to failure in hot forging. The failure mechanism of hot forging dies has been studied by Gronostajski et al. [7]. They found that thermomechanical fatigue is the factor affecting most die because it produces fine cracks that extend over the entire contact surface. This phenomenon, together with oxide abrasive particles from hot material, contributes to a sharp rise in abrasive wear.

Knowing and respecting the forging optimum temperature for each material is another decisive factor for the success forging process. Ghanbari et al. [8] were occupied of manufacturing a nanostructured Ti-6Al-4V alloy by closed die forging along several axes, in isothermal conditions. The same material is studied in their paper by Gupta et al. [9]. Two manufacturing variants were investigated, closed die forging of pressure vessels from titanium alloy Ti6Al4V: one with several stages of forging and mill annealing and one by one / two step forging and mill annealing.

Sedighi and Pourbashiri $[10,11]$ were concerned to reduce material waste in closed die forging. They proposed a new method, called variable gutter technique, which resulted in a decrease of about $50 \%$ of waste material from one forged part.

This paper presents a case study for closed die forging of a gear. The study shows finite element analysis, performed in order to determine the influence of channel flash dimensions on forging pressure and force to optimize the forging process.

\section{Process description}

A numerical simulation of a closed die forging process in one step, to a gear (Fig. 1.a) is presented. Flash dimensions have great influence on: forging load, forging energy and durability dies. Channel flash plays an important role in achieving a proper flow of the material in the finisher cavity. Depending on the complexity of the forged part, there are different constructive channels forms that can be used, most used flash channel being the one with the shape shown in Fig. 1.b. Flash channel consists of two main parts: the flash land (with the dimensions $w_{1}$ and $h_{1}$ ) and flash gutter (with the dimensions $w_{2}$ and $h_{2}$ ).

To establish the dimensions of the flash channel, flash land height $h_{1}$ is first determined, as follows:

- For the forging hammers,

$$
h_{1}=0.015\left(A_{p}\right)^{1 / 2}
$$


- For the forging presses,

$$
h_{1}=0.020\left(A_{p}\right)^{1 / 2}
$$

$A_{p}$ being part's area in the parting line.

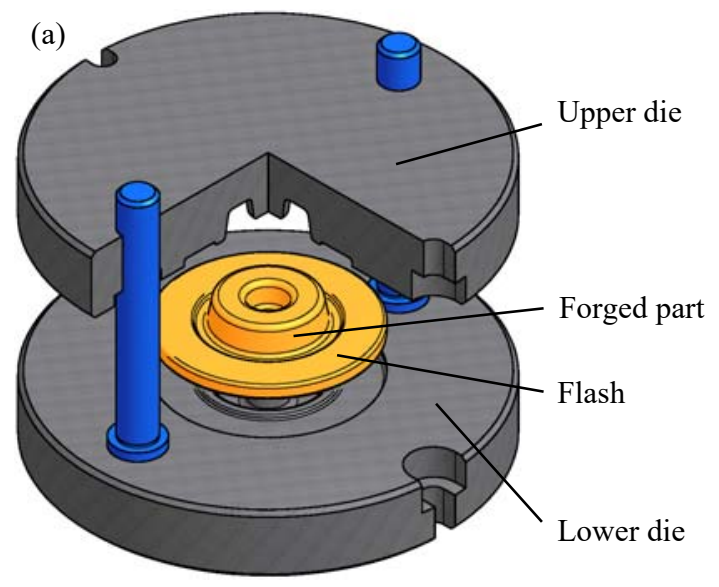

(b)

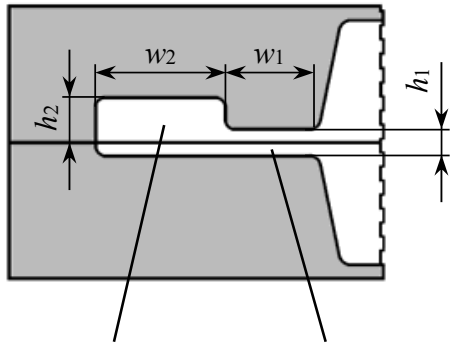

Flash gutter $\quad$ Flash land

Fig. 1. 3D model of the studied forged part (a) and the dimensions of a flash channel (b).

The relationships (1) and (2), empirically determined and used in practice, can be improved by numerical simulation. The values calculated by these relationships can be corrected (by increasing or decreasing the value of $h_{1}$ ) after examining how the flow of the material for any type of forged part, in order to optimize the forging process. After calculating the flash land height $h_{1}$, other dimensions of the flash channel $w_{1}, w_{2}$ and $h_{2}$ are extracted from tables after previously was provided the flow mode of material into cavity.

The type of finite element analysis chosen was coupled elastic-plastic analysis, which enables establishing the dependency between stress and the temperature from process. Forging process occurs with the transfer of heat to the environment, which is calculated based on the updated shape (workpiece) after each increment and contact conditions. A fraction of the energy for plastic deformation is converted into heat and the friction between the dies and the workpiece, also produces heat. Coupled analysis considers the effect of temperature changes on the forged material properties. Because of the axial-symmetric geometry of the forged part, the simulation can be more efficient in terms of time analysis by adopting a $2 \mathrm{D}$ model analysis. The material model used is the elastic-plastic with hardening, the material is assumed to be isotropic and von Mises plasticity criterion was used in the analysis. The workpiece was defined as a deformable body, was meshed by a number of 300 quadrilateral finite elements and an adaptive remeshing method was selected. The two dies, the lower fixed and upper mobile, were defined as rigid bodies and meshed with a number of 2146 triangular finite elements. Material data for the workpiece used in experiment, and for dies are shown in Table 1.

Table 1. Material data for workpiece and dies.

\begin{tabular}{|l|c|c|l|c|c|}
\hline $\begin{array}{c}\text { Mechanical } \\
\text { characteristics }\end{array}$ & $\begin{array}{c}\text { Work- } \\
\text { piece }\end{array}$ & Dies & \multicolumn{1}{|c|}{$\begin{array}{c}\text { Thermal } \\
\text { characteristics }\end{array}$} & $\begin{array}{c}\text { Work- } \\
\text { piece }\end{array}$ & Dies \\
\hline Young's modulus $[\mathrm{MPa}]$ & 14000 & 217000 & Thermal expansion $[1 / \mathrm{K}]$ & $2.93 \times 10^{-5}$ & $1.05 \times 10^{-5}$ \\
\hline Poisson's ratio & 0.3 & 0.3 & Conductivity $[\mathrm{W} / \mathrm{m} \cdot \mathrm{K}]$ & 24 & $45.1 \times 10^{3}$ \\
\hline Mass density $\left[\mathrm{kg} / \mathrm{m}^{3}\right]$ & 11360 & 7850 & Specific heat $[\mathrm{J} / \mathrm{kg} \cdot \mathrm{K}]$ & 129 & $371 \times 10^{3}$ \\
\hline
\end{tabular}


The initial temperature of the workpiece at the start of the forging process is $20^{\circ} \mathrm{C}$. Contact conditions were established by specifying the coefficient of heat transfer with the environment for the workpiece, the coefficient of contact heat transfer and the initial temperature $\left(20^{\circ} \mathrm{C}\right)$ for dies and the coefficient of friction between the dies and the workpiece $(\mu=0.3)$. The friction coefficient between the dies and the workpiece is assumed to be constant along the contact surfaces.

\section{Results and discussions}

The first results and analyzes undertaken followed the flow behaviour of the material and variations stresses, strains and temperature in the workpiece volume during the forging.

Some results regarding the stress, strain and temperature fields from the forged part are graphically illustrated in Fig. 2. In it is observed that all dies corners are well filled with material before it flows in the flash through the land. This shows that the flash channel dimensions were well designed so that it is ensured that firstly filling of the cavity corresponding to the forged part is complete and then excess material passes to the flash.

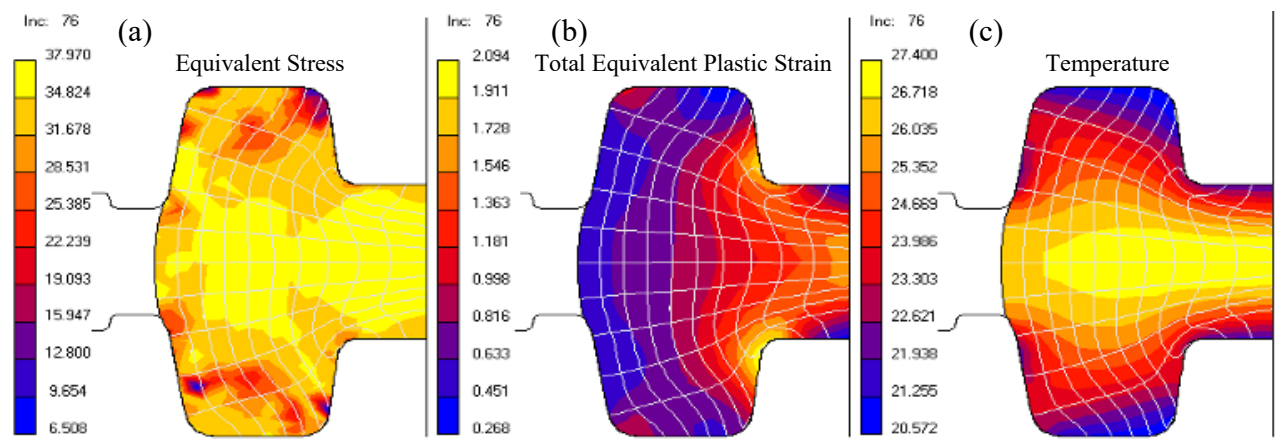

Fig. 2. Variation fields: (a) equivalent stress [MPa]; (b) equivalent plastic strain; (c) temperature $\left[{ }^{\circ} \mathrm{C}\right]$.

Images concerning the fields of stress and strain were also obtained for both the equivalent and their components, for any increment of time from the forging process.

Next, equivalent stresses from closed forging dies were analyzed, for various dimensions of the flash channel in order to optimize the process. Three different cases of flash channel dimensions were chose to be analyzed, shown in Table 2.

Table 2. The cases studied for flash dimensions.

\begin{tabular}{|l|c|c|c|}
\hline $\begin{array}{c}\text { Dimensions } \\
{[\mathrm{mm}]}\end{array}$ & Case I & Case II & Case III \\
\hline Height, $h_{1}$ & 1 & 0.5 & 2 \\
\hline Height, $h_{2}$ & 4 & 3 & 6 \\
\hline Width, $w_{1}$ & 6 & 6 & 6 \\
\hline Width, $w_{2}$ & 20 & 20 & 20 \\
\hline
\end{tabular}

The maximum values of stresses from dies are recorded at the end of the forging process. In Fig. 3 it can be observed that stresses have maximum values at the outer corners of the dies, but do not exceed the allowable strength at break of the steel from which dies are made (42CrMo4). This shows that the corner radius may be increased to ensure easy flow of the material in that area. The maximum value of forging force is achieved with the dies' closure. 
An analysis of data obtained for the three simulated cases can be done by examining the graph from Fig. 4 . The forging forces values show that by halving the flash land height $\left(h_{1}\right)$ the force increases by about $71 \%$ (case II) and through doubling the height, forging force decreases by about $13 \%$ (case III). Maximum equivalent stresses of dies, compared to the case I which is considered a reference, increase by about $66 \%$ in case II and have an insignificantly change in case III (about 3\%).

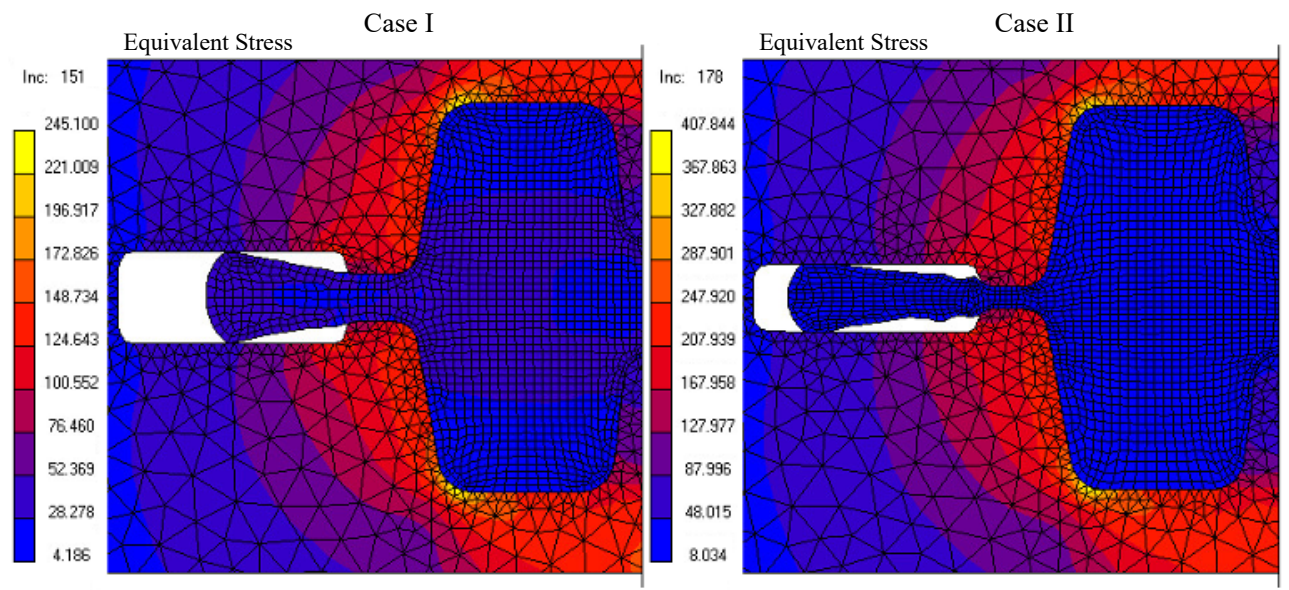

Fig. 3. Variation field of equivalent stress $[\mathrm{MPa}]$ from dies in two studied cases.

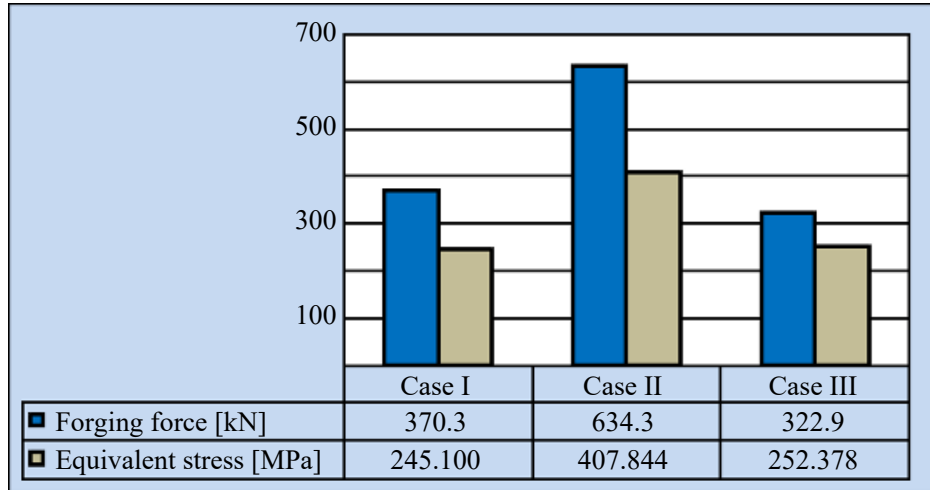

Fig. 4. The maximum values of forging forces and stresses from dies in the three cases.

After obtaining finite element model it is important to check the agreement between this and the experimental model that it represents. Verification is required for validation of the model obtained and this is made by comparing the some parameters obtained by measuring from experiments, with values of the same parameters determined by simulation. Experimental tests were carried out on a hydraulic press of 75 tonnes and a lead $(\mathrm{Pb})$ workpiece with the dimensions $\varnothing 40 \times 75 \mathrm{~mm}$ was used. Experimental data acquired were: forging force $[\mathrm{kN}]$, forging pressure $[\mathrm{MPa}]$ and press ram stroke $[\mathrm{mm}]$. The experimental obtained part can be seen in Fig. 5.a.

Comparison of numerical data obtained by simulation with experimental data was done for forging force. The two variations of forging force with press ram stroke show a good agreement between the numerical data and those from the experiments (Fig. 5.b).

In finite element modelling, the compatibility between material model, physical model and type of analysis is very important. If simulations are conducted with proper models, it can generate results sufficiently accurate for the modelling to be taken into account. 

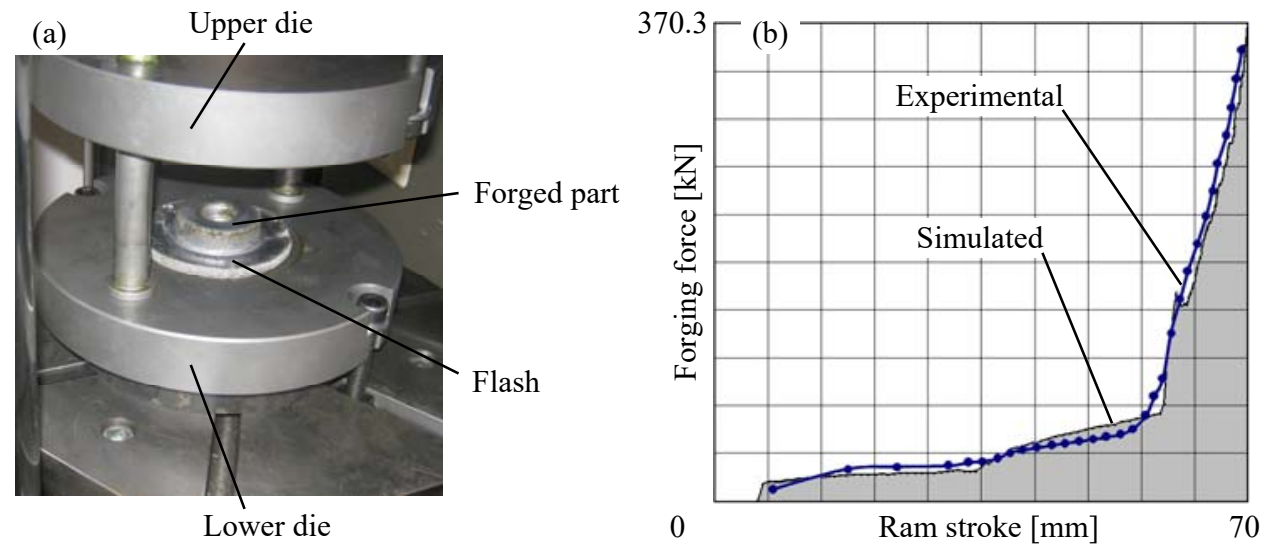

Fig. 5. Forged part obtained experimentally (a) and forging force vs. ram stroke for case I (b).

The results presented in Fig. 5.b show that the finite element model developed provide accurate data for numerical analysis performed in this paper.

\section{Conclusions}

In the case of closed die forging process numerically analyzed, it was noticed a good agreement between the data obtained by means of the finite element model developed and data acquired from experiments. Thus, forging force values extracted from finite element modelling results show a deviation of about $12 \%$ from the forging force recorded in the laboratory.

The main conclusions are: $(i)$ Equivalent stresses from forging tools vary inversely with the flash land height; (ii) Forging force decreases with increasing of the flash land height however, increasing the flash land height can be made only within the limits in which ensures a complete filling of final cavity corners; (iii) Equivalent elastic strains in the dies, for all three cases considered, are low, below $1 \mu \mathrm{m}$ (the maximum is 0.4 than $0.5 \mu \mathrm{m}$ ); it shows that the dies were well designed, are sufficiently rigid and provide the necessary precision for the forged part.

\section{References}

1. C. Brecher, W. Klein, M. Tannert, Prod. Eng. Res. Devel. 4, 279 (2010)

2. T. Altan, M. Shirgaokar, Process Design in Impression Die Forging, Chapter 14, https://ercnsm.osu.edu/sites/ercnsm.osu.edu/files/uploads/F-hotforging/467.pdf, accessed 05.02.2017

3. B. Tomov, R. Radev, Int. J. Mater. Form., 3 (1), 319 (2010)

4. K. Wei, H. Yang, X. Fan, P. Gao, Int. J. Adv. Manuf. Technol., 81, 729 (2015)

5. S.Z. Chavoshi, Int. J. Interact. Des. Manuf., Published online: 20 November 2014, http://link.springer.com/article/10.1007/s12008-014-0256-x, accessed 21.02.2017

6. S. Abachi, M. Akkok, M.I. Gokler, Tribol. Int., 43, 467 (2010)

7. Z. Gronostajski, M. Kaszuba, S. Polak et al., Mat. Sci. Eng. A-Struct, 657, 147 (2016)

8. B.F. Ghanbari, H. Arabi, S.M. Abbasi, S.M. Ali Boutorabi, Int. J. Adv. Manuf. Technol., 87, 755 (2016)

9. R.K. Gupta, V.A. Kumar, P.R. Kumar, J. Mater. Eng. Perform., 25, 2551 (2016)

10. M. Sedighi, M. Pourbashiri, J. Mech. Sci. Technol., 28 (12), 5129 (2014)

11. M. Pourbashiri, M. Sedighi, J. Mech. Sci. Technol., 30 (4), 1851 (2016) 